\title{
Effect of Extrusion Direction on Microstructure and Corrosion Behavior of Rare Earth doped AZ91 Alloy
}

\author{
Xiaoyu Fu ${ }^{1}$, Ruiling Jia, ${ }^{1, *}$ Feng Guo ${ }^{1}$,Wen Ma ${ }^{1}$, Huixia Zhang ${ }^{2}$, Jian $\mathrm{Hou}^{2}$ \\ ${ }^{1}$ Inner Mongolia Key Laboratory of Thin Film and Coatings, School of Materials Science and \\ Engineering, Inner Mongolia University of Technology \\ ${ }^{2}$ State Key Laboratory of marine corrosion and protection, 725 Research Institute of China \\ Shipbuilding Industry Corporation, Qingdao 266101 \\ *E-mail: jr1014014@163.com
}

doi: $10.20964 / 2020.12 .20$

Received: 1 August 2020 / Accepted: 20 September 2020 / Published: 31 December 2020

By studying the changes in the grain size of $\alpha-\mathrm{Mg}$ matrix, the distribution and size of the intermetallic phases in the transverse and longitudinal sections of the extruded AZ91 alloy with $1.0 \%$ (La, Ce) mischmetal (MM) addition, in combination with the corrosion behavior on the transverse and longitudinal sections, the corrosion mechanism of them caused by the change of microstructure was revealed. The results showed that a grain refinement and size reducing in $\beta-\mathrm{Mg}_{17} \mathrm{Al}_{12}$ and $\mathrm{Al}_{4}(\mathrm{La}, \mathrm{Ce})$ phases had been found in extruded alloy. The relative potential difference of the intermetallic phases was influenced by extrusion process, the one between the $\mathrm{Al}_{4}(\mathrm{La}, \mathrm{Ce})$ phase and $\mathrm{Mg}$ matrix in the longitudinal section of the extruded alloy is the highest, but $\mathrm{Al}_{4}(\mathrm{La}, \mathrm{Ce})$ phase was a weak cathode. The decrease in the size of $\beta-\mathrm{Mg}_{17} \mathrm{Al}_{12}$ reduced the area of the cathode of the micro-galvanic coupling, the change of the size of $\mathrm{Al}_{4}(\mathrm{La}, \mathrm{Ce})$ phase has no remarkable effect on the micro-galvanic corrosion behavior. Corrosion morphologies were varied with difference in extrusion direction, the corrosion morphology in the transverse section is mainly pitting corrosion caused by the cathode phases of $\beta$ $\mathrm{Mg}_{17} \mathrm{Al}_{12}$ and individual $\mathrm{Al}_{4}(\mathrm{La}, \mathrm{Ce})$. The corrosion morphology in the longitudinal section are characterized by corrosion streamline parallel to extrusion direction, the corrosion occurs at the grain boundaries of the recrystallized grain.

Keywords: Magnesium Alloy; Rare earth; Extrusion; Corrosion

\section{$\underline{\text { FULL TEXT }}$}

(C) 2021 The Authors. Published by ESG (www.electrochemsci.org). This article is an open access article distributed under the terms and conditions of the Creative Commons Attribution license (http://creativecommons.org/licenses/by/4.0/). 